\title{
Preparation and properties of natural rubber reinforced with polydopamine-coating modified carbon nanotubes
}

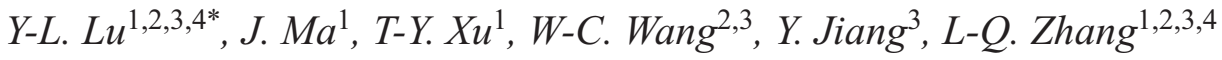 \\ ${ }^{1}$ Key Laboratory of Organic-Inorganic Composites, Beijing University of Chemical Technology, 100029 Beijing, P. R. \\ China \\ ${ }^{2}$ Key Laboratory of Beijing City for Preparation and Processing of Novel Polymer Materials, Beijing University of \\ Chemical Technology, 100029 Beijing, P. R. China \\ ${ }^{3}$ Key Laboratory of Carbon Fiber \& Functional Polymers, Beijing University of Chemical Technology, 100029 Beijing, \\ P. R. China \\ ${ }^{4}$ Center of Advanced Elastomer Materials, College of Material Science and Engineering, Beijing University of Chemical \\ Technology, 100029 Beijing, P. R. China
}

Received 11 June 2016; accepted in revised form 15 August 2016

\begin{abstract}
Multi-walled carbon nanotubes (MWCNTs) were functionalized by polydopamine (PDA)-coating and mixed with natural rubber (NR) via latex compounding. Compared with pristine MWCNTs, the surface of MWCNT-PDA was covered by an amorphous and nanometer-scale PDA layer which had a large amount of oxygenic and nitric functional groups. So the MWCNT-PDA showed a perfect dispersion in NR matrix. The tensile strength of NR/MWCNT-PDA ( 5 phr) composites is 28.6 MPa, compared with the pure NR, which increased by $42 \%$. For the electrical properties, when the content of MWCNTPDA or MWCNTs is $2 \mathrm{phr}$, the volume resistivity of NR/MWCNT-PDA composites falls to about $2.7 \cdot 10^{9} \Omega \cdot \mathrm{cm}$, compared with $3.3 \cdot 10^{13} \Omega \cdot \mathrm{cm}$ of NR/MWCNT composites. The thermal conductivity of NR composites increased only by $28.2 \%$ when 5 phr MWCNT-PDA was added. A model proposed by Nan was used to calculate the thermal conductivity of NR/MWCNT composites, and the calculated values were compared with the experimental values, the results showed that the interface thermal resistance is the main reason why MWCNTs could not significantly increase the thermal conductivity of natural rubber.
\end{abstract}

Keywords: nanocomposites, dopamine, natural rubber, mechanical properties, electrical conductivity

\section{Introduction}

NR is one of the most important nature polymers, which is widely used as the elastomeric matrix of various materials, including conveyor belts, sealing rings, tires, etc. In order to meet the requirements of the use of tires, NR composites must have the following two properties: (1) good mechanical properties, in order to undergo cyclic loading and strains in actual use, (2) good thermal conductivity and electrical conductivity, in order to export the heat or static electricity effectively and timely. However, traditional fillers (such as carbon black, silica, alumina, etc.) cannot improve both aspects simultaneously, though the high surface carbon blacks may improve both mechanical properties and electrical conductivity, but the precondition is that a relative large amount of high surface carbon black must be added, this may adversely affect the processing performance of the composites. Recently, the carbon nanotubes (CNTs) have become a hot spot in various research fields for their unique structure and outstanding performances $[1,2]$. High mechanical properties (tensile strength is $\sim 50 \mathrm{GPa}$, Young modulus is $\sim 5 \mathrm{TPa}$ ) and good conductivity (electrical conductivity is $\sim 10^{7} \mathrm{~s} / \mathrm{m}$, thermal

$\overline{{ }^{*} \text { Corresponding author, e-mail: luyonglai@hotmail.com }}$ (C) BME-PT 
conductivity is $\sim 3000 \mathrm{~W} /(\mathrm{m} \cdot \mathrm{K})$ have made CNTs become one of the ideal fillers for rubber materials. So, the researches on rubber/CNT composites are developing rapidly in recent 5 years [3-5]. But the actual improvements brought by pristine CNTs are not as remarkable as expected, particularly on the strength of rubber [6-8]. Nakaramontri et al. [9] have showed that the values of tensile strength decreased when raw CNTs were added to the nature rubber matrix. Fritzsche et al. [10] have shown that the tensile strength and elongation at break of natural rubber/ CNTs (100/10) were 17.32 MPa and 302.7\%, compared with $14.27 \mathrm{MPa}$ and $467.6 \%$ of pure natural rubber, and they considered the agglomerations of CNTs in matrix as the main reason for the inconspicuous effects. Nah et al. [11] have reported that the interaction between CNTs (without modification) and natural rubber was mainly caused by physical entanglement, rather than strong interfacial adhesion, so the interaction was weak and easy to break down when stretched. Therefore, improving the poor dispersion of CNTs in rubber and enhancing the interfacial interaction between each other are the two challenges in the further research.

Due to the high aspect ratio of the nanotubes and the Van der Waals' force between nanotubes, CNTs exist almost in the form of agglomerates, which is hard to break down even under ultrasonic vibration. What's more, few defects and the lack of active functional groups on surfaces make CNTs a chemically inert substance. So, the modification of carbon nanotubes is one of effective methods to solve the problems about aggregation and chemical inertia of carbon nanotubes. As reported in many literatures, acid treatment [12] and oxidation [13] were considered as the most direct and effective pretreatments for CNTs. Not only could they break down the entanglements, but they could also introduce oxygen functional groups (such as carboxyl, hydroxyl, etc.) on the surfaces of CNTs. However, this kind of modification inevitably destroys the structure of CNTs, resulting in the corrosions of graphite crystal layer and the decrease of high aspect ratio. It is well acknowledged that the integrity of CNTs' structure is the precondition of its thermal performances [14]. So the properties of CNTs modified by these methods may not be as good as the original ones. In our opinion, using a mild method to modify CNTs is the first and critical step for preparing CNTs composites.

Furthermore, it is important to choose an appropriate method to prepare rubber/CNT composites. There are mainly three methods reported by literatures: melt mixing [15], solution blending [16] and latex compounding [17]. The traditional melt mixing is considered as the most convenient and practical way, but the shear force produced by mixing CNTs and rubber is not strong enough to destroy the entanglements of CNTs. Although solution blending can disperse CNTs in rubber evenly, the use and recycling of organic solvent not only make the process complicated, but also bring about some environmental problems. Latex compounding is a novel and effective method. There are two steps in its detailed process: (1) mixing the CNTs suspension with latex; (2) drying and curing the mixture at different temperatures. The mechanism of latex compounding is similar with solution blending, but the former ensures the uniform dispersion of CNTs in matrix, and avoids the shortcoming of latter.

Recently, it was reported that mussel adhesive proteins could form strong adhesive interactions between mussel and various substrates in wet environment, and the critical element of this protein was 3 , 4-dihydroxyphenethylamine (dopamine, or DA) [18]. Inspired by this, many researchers began to use dopamine as a surface modifier for other materials [19-21]. However, the most attractive feature of this modification is that the PDA layers could bring in active functional groups (hydroxyl, amino etc.) without damaging the structure of the matrix. In this work, the idea of improving the interfacial interaction between MWCNTs and rubber with PDA-coating layers was firstly put forward. The MWCNTs were added into dopamine aqueous solution to prepare PDA-modified MWCNTs; then the natural rubber (NR) composites filled with MWCNT-PDA was prepared by latex compounding. Furthermore, the structure and composition of pristine MWCNTs and MWCNTPDA were characterized and compared. And the microstructure and properties of NR/MWCNT-PDA composites (including mechanical properties, electrical and thermal conductivity) were also characterized and discussed in detail. 


\section{Experimental}

\subsection{Materials}

The pristine MWCNTs (diameter: 10 20 nm; length: 1 10 $\mu \mathrm{m}$; purity: $\geq 95 \%$ ) were obtained from CNano Technology Co. (PR China). Dopamine was offered by Sigma Co. (USA). The 2-amino-2- (hydroxymethyl)-1, 3-propanediol (Tris) was purchased from Alfa Aesar Co. (USA). The natural latex with a total solid content of $59 \%$ was sourced from Natural rubber industry Co. (PR China).

\subsection{Modification of MWCNTs by PDA}

The pristine MWCNTs were dispersed in deionized water (MWCNTs $/ \mathrm{H}_{2} \mathrm{O}: 1 \mathrm{~g} / 500 \mathrm{~mL}$ ) by ultrasonic treatment for 1 hour (h). Then the Tris, which was used as $\mathrm{pH}$ buffering agents, was added into the MWCNTs suspension (Tris/ $\mathrm{H}_{2} \mathrm{O}: 10 \mathrm{mM} / \mathrm{L}$ ), and dilute $\mathrm{HCl}$ was dipped into the suspension to adjust $\mathrm{pH}$ value (pH: 7 8) simultaneously. The dopamine powder was also added into the suspension (Dopamine/ $\mathrm{H}_{2} \mathrm{O}: 2 \mathrm{~g} / \mathrm{L}$ ). After stirring at room temperature for $24 \mathrm{~h}$, the MWCNTs coated by PDA were washed and filtered until the filtrate was colorless and transparent [22]. And the MWCNT-PDA were kept waterish, which could facilitate the further mixture with natural latex.

\subsection{Preparation of natural rubber based composites}

The formulation of composites is showed in Table 1. Sulphur, accelerant and other ingredients are commercially available industrial products. There were two steps in the preparation of the composites. For step one, the incorporation of MWCNT-PDA into NR latex was carried out by latex compounding. MWCNT-PDA were dispersed in deionized water with $0.5 \mathrm{~h}$ ultrasonic treatment. Subsequently, the MWCNT-PDA suspension was mixed with natural

Table 1. Formulation

\begin{tabular}{|l|c|}
\hline \multicolumn{1}{|c|}{ Component } & Phr $^{\mathbf{a}}$ \\
\hline Natural rubber & 100 \\
\hline Zinc oxide & 5 \\
\hline Stearic acid & 2 \\
\hline Diphenyl guanidine (DPG) & 0.5 \\
\hline Dibenzothiazole disulfide (DM) & 0.5 \\
\hline Tetramethylthiuram disulfide((TMTD) & 0.2 \\
\hline Sulphur & 2 \\
\hline MWCNTs-PDA or MWCNTs & $0-5$ \\
\hline
\end{tabular}

aarts by weight per hundred parts of rubber. latex under high-speed stirring. Then the mixture was poured into dilute sulfuric acid solution ( $3 \mathrm{wt} \%$ ) for demulsification; the flocculated product was cut into small pieces and dried at $60^{\circ} \mathrm{C}$. The masterbatch was obtained according to the descriptions above. For step two, the sulphur and accelerant were added into the masterbatch by melt mixing in an open two-roll mill. The mixing temperature was controlled under $50^{\circ} \mathrm{C}$, and the time was less than 15 minutes. For comparison, the NR/MWCNT composites were prepared by the same method. In the preparation process of NR/ MWCNT-PDA composites, in order to unify the variable, the amount of MWCNT-PDA is the same as that of MWCNTs.

PDA was prepared as following procedure: the dopamine powder was added into the deionized water (Dopamine/ $\mathrm{H}_{2} \mathrm{O}: 2 \mathrm{~g} / \mathrm{L}$ ), then the Tris was added into the solution (Tris $/ \mathrm{H}_{2} \mathrm{O}: 10 \mathrm{mM} / \mathrm{L}$ ), and dilute $\mathrm{HCl}$ was dipped into the solution to adjust $\mathrm{pH}$ value $(\mathrm{pH}$ : 7 8) simultaneously. After stirring at room temperature for $24 \mathrm{~h}$, the oxidative polymerization of dopamine is substantially completed, The product was collected by filtration and washed with deionized water until the filtrate was colorless and finally dried in vacuum oven at $80^{\circ} \mathrm{C}$ overnight.

The obtained PDA was added in deionized water and stirred until it dissolved completely. Subsequently, the PDA solution was mixed with natural latex under high-speed stirring. Then the mixture was poured into dilute sulfuric acid solution ( $3 \mathrm{wt} \%$ ) for demulsification; the flocculated product was cut into small pieces and dried at $60^{\circ} \mathrm{C}$. In the masterbatch; the mass ratio of NR to PDA was 100: 0.5 (100 phr dry natural rubber: $0.5 \mathrm{phr}$ PDA). The sulphur and accelerant were mixed with the masterbatch homogenously using a two-roll mill.

\subsection{Characterizations}

The surface morphologies of MWCNT-PDA were observed by high resolution electron microscope (JEM3010 , JEOL, Japan) with an accelerating voltage of $300 \mathrm{kV}$. Thermal analysis instruments (TGS-2, Perkin-Elmer Co. USA) were used to quantify the content of PDA on the MWCNTs. The samples were heated from 20 to $800^{\circ} \mathrm{C}$ at a heating rate of $10 \mathrm{~K} / \mathrm{min}$ under nitrogen flow. To measure the degree of functionalization, X-ray photoelectron spectroscopy (XPS) measurements (ESCALAB 250, Thermo Elec- 
tron Co., America) were carried out on MWCNTsPDA.

In order to observe the dispersion of MWCNT-PDA in NR composites, HR-TEM was performed on the samples with $\sim 100 \mathrm{~nm}$ thickness prepared by cryo ultra microtome (FC6 UC6, Leica, Germany). Strainsweep experiments on the mixing compounds were performed by a rubber processing analyzer (RPA 2000, Alpha Co., USA). The test condition is as following: temperature was $60^{\circ} \mathrm{C}$, the frequency was $1 \mathrm{~Hz}$, the shear strain amplitude varied from $0.28 \%$ to $100 \%$, and the test configuration is stretch mode. The vulcanization behavior of neat NR and NR composites were determined at the processing temperature of $143^{\circ} \mathrm{C}$ using a rotorless rheometer (P3555B2, Beijing Huanfeng Chemical technology and Experiment Machine Plant, PR China). Tensile properties of all vulcanizates were measured with a tensile tester (CMT4104, Shenzhen New Batching Technology Co., PR China) according to Chinese standard GB/T 528-1998. The hardness of composites was carried out using a Shore A durometer. The volume resistivity of rubber samples $(80 \mathrm{~mm}$ in diameter and $2 \mathrm{~mm}$ in thickness) was measured by a digital insulated resistor tester (PC68, Shanghai, PR China). Thermal conductivity tester (HC-110, Laser Co., USA) was performed to measure the thermal conductivity of samples according to standard D5470 formulated by ASTM. The dimensions of the samples for this experiment were $60 \mathrm{~mm}$ in diameter and $6 \mathrm{~mm}$ in thickness. The crosslink density was determined using equilibrium swelling method. The vulcanized samples were put into toluene at room temperature for $72 \mathrm{~h}$ to achieve equilibrium swelling. The swollen samples were weighed and then dried at $80^{\circ} \mathrm{C}$ until the weight was constant. The crosslink density was calculated according to Flory-Rehner equation (Equation (1)) [23]:

$\operatorname{In}\left(1-\varphi_{\mathrm{r}}\right)+\varphi_{\mathrm{r}}+\chi \varphi_{\mathrm{r}}^{2}=-n_{\mathrm{c}} V_{\mathrm{s}}\left[\varphi_{\mathrm{r}}^{1 / 3}-\frac{\varphi_{\mathrm{r}}}{2}\right]$

where the $\varphi_{\mathrm{r}}$ is the volume fraction of polymer in the swollen sample; $\chi$ is the polymer-solvent interaction parameter; $V_{\mathrm{s}}$ is the molar volume of solvent $\left[\mathrm{cm}^{3} / \mathrm{mol}\right] ; n_{\mathrm{c}}$ represents the crosslink density of polymer $\left[\mathrm{mol} / \mathrm{cm}^{3}\right]$.

\section{Results and discussion}

\subsection{The effect of dopamine on MWCNTs}

The oxidative polymerization of dopamine spontaneously occurs under suitable condition, and PDA, the product of oxidative polymerization, can adhere to the surface of any given substrates. The benzene rings which exist in the polydopamine can form $\pi-\pi$ stacking interaction with carbon nanotubes [20]. This made it possible to coat MWCNTs by PDA. The schematic illustration is showed in Figure 1. The coating layers could not only improve the hydrophilism of MWCNTs, but also might increase the adhesive interactions between MWCNTs and NR.

Figure 2 displays the HR-TEM images of pristine MWCNTs and MWCNT-PDA. It is clearly found that the outer diameter of pristine MWCNTs is $\sim 15 \mathrm{~nm}$; the graphite sidewall of pristine MWCNTs is smooth and neat. However, after modification with PDA films, it can be seen from Figure $2 b$ that the diameter of MWCNT-PDA increased by about $6 \mathrm{~nm}$, the surface of MWCNT is no longer neat; there is a layer of amorphous substance on the surface of the carbon nanotubes, which should represent PDA layer.

Figure 3 shows the dispersions of MWCNTs and MWCNT-PDA in water after $0.5 \mathrm{~h}$ ultrasonic vibra-

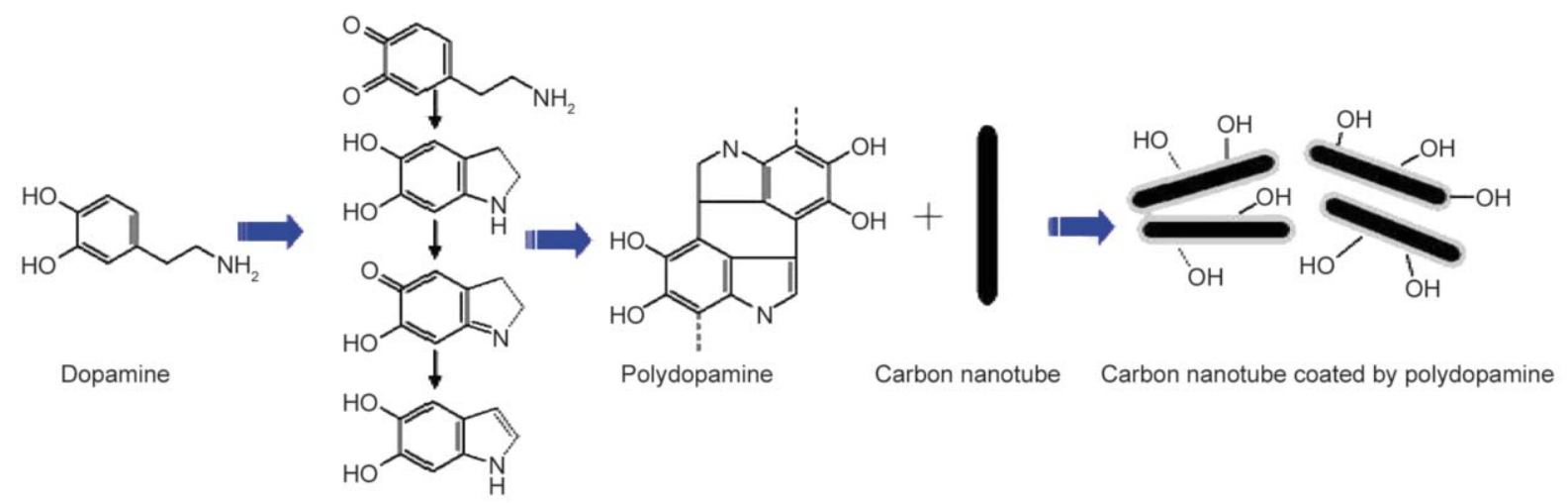

Figure 1. The schematic diagram illustrating the processes of coating CNTs with PDA 


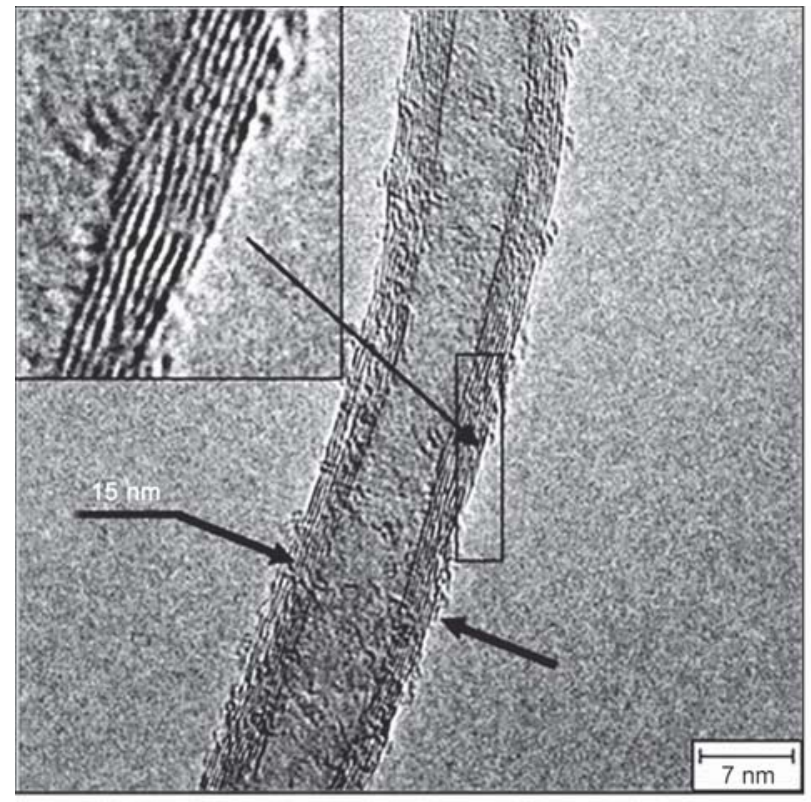

a)

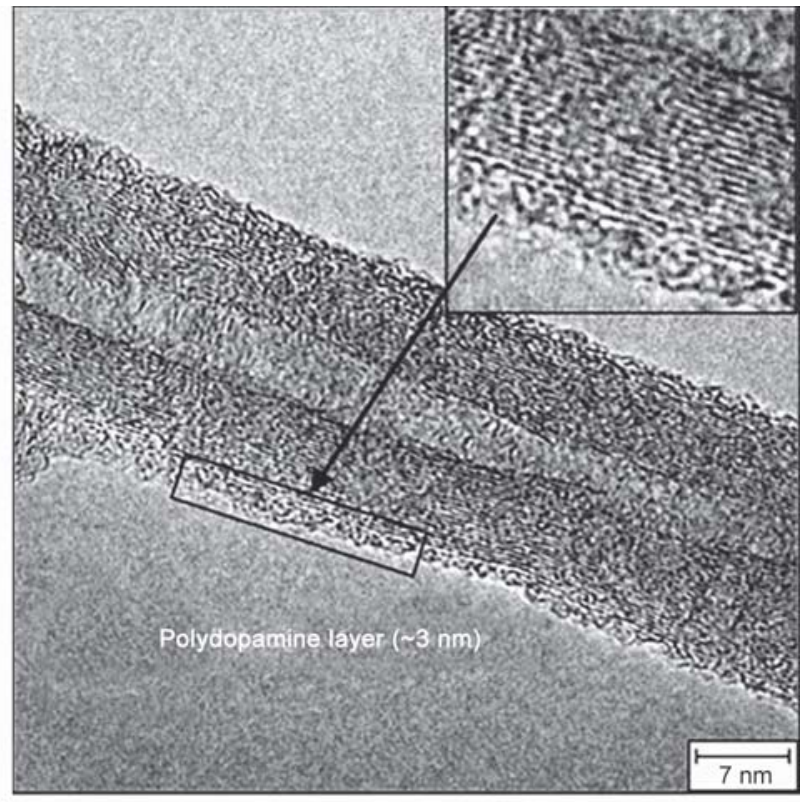

b)

Figure 2. HR-TEM images of pristine MWCNTs (a) and MWCNTs-PDA (b)

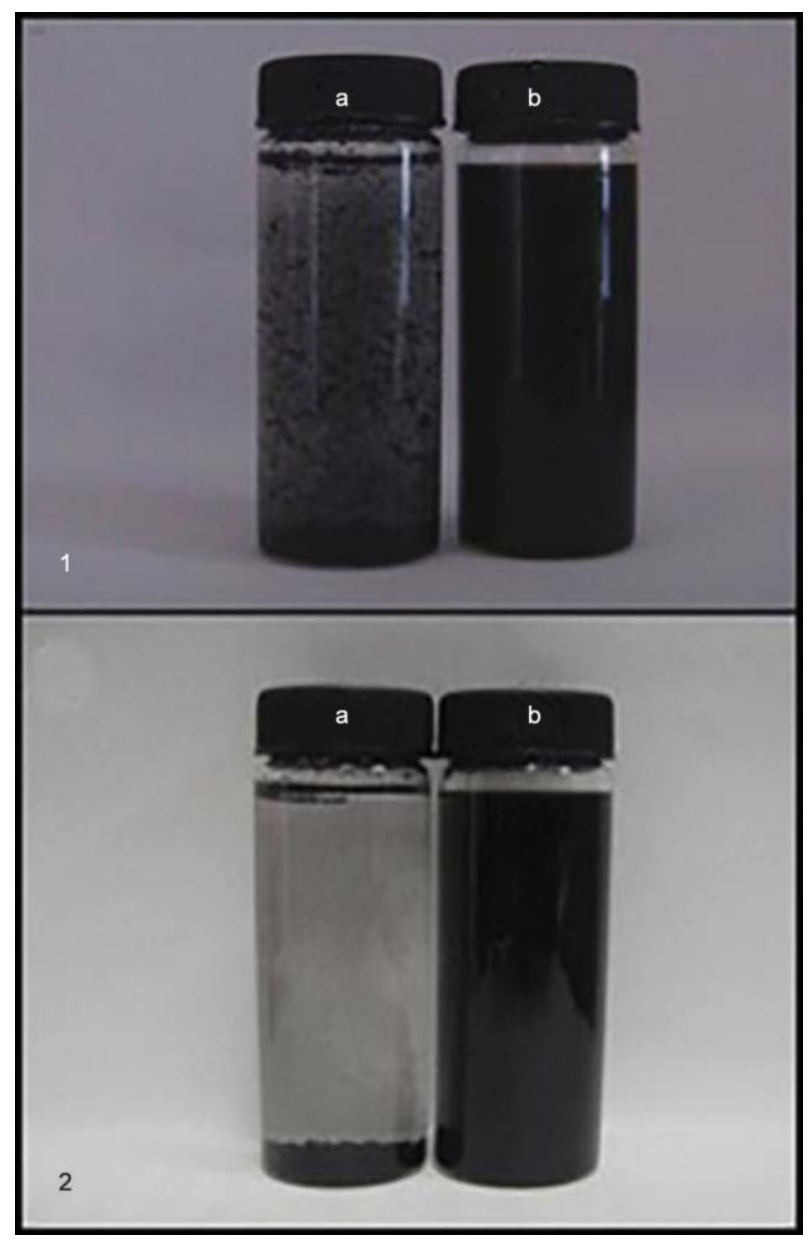

Figure 3. The photographs of dispersion of pristine MWCNTs (a) and MWCNTs-PDA (b) in water after 0.5 h ultrasonic vibration: 1 . staying for 0.5 hour; 2. staying for 1 week tion treatment. As mentioned above, the entanglements of pristine MWCNTs can't be broken down even via ultrasonic treatment. So, a lot of granular black solids dispersing in the water can be seen, and after 1 week, the phenomenon of precipitation occurs. But the MWCNT-PDA/water suspension after ultrasonic vibration looks like black ink and maintains this state at least 1 week. It can be explained that the existence of PDA coating not only increases the steric hindrance between MWCNTs, but also introduces hydrophilic groups on the surface of MWCNTPDA. Those groups greatly improve the water dispersibility of MWCNT-PDA. So the entanglements of MWCNT-PDA could be broken down easily under ultrasonic vibration and disperse in deionized water steadily for a long time without deposition.

Based on the different thermal stability of MWCNTs and its coatings, TGA is often performed to examine the content of coating on MWCNTs [24, 25]. Figure 4 shows the weight loss curve of pristine MWCNTs and MWCNT-PDA. Obviously, the pristine MWCNTs have good thermal stability. The weight loss of pristine MWCNTs is about $2.1 \%$ when the temperature reaches to $800^{\circ} \mathrm{C}$ while the weight loss is $12.5 \%$ for MWCNT-PDA, which is attributed to the thermal degradation of PDA with the rising temperature. So, the content of PDA was estimated to be $10.4 \%$.

As shown in Figure 5, there are two characteristic peaks in the XPS spectrum of pristine MWCNTs: the 


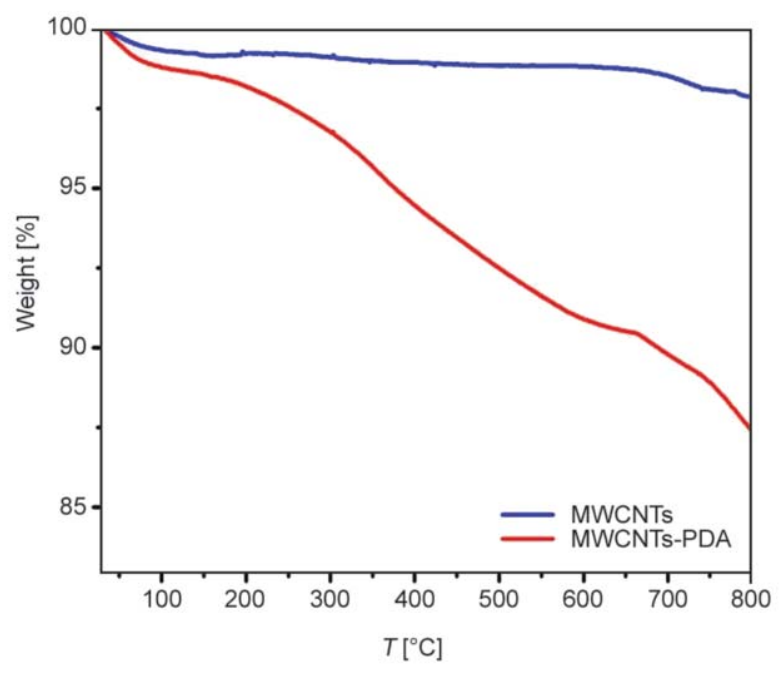

Figure 4. The weight loss curve of pristine MWCNTs and MWCNTs-PDA

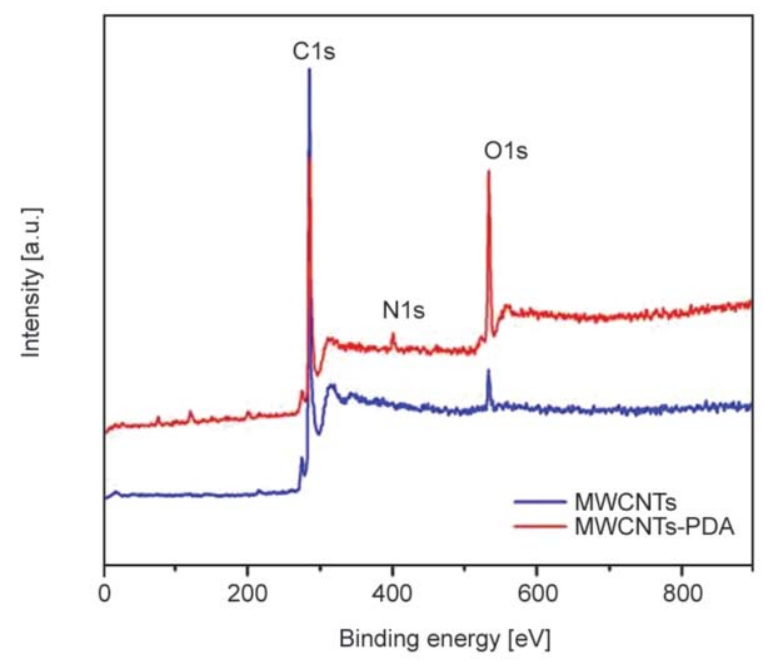

Figure 5. The XPS spectrum diagrams of pristine MWCNTs and MWCNTs-PDA

$\mathrm{C} 1 \mathrm{~s}$ peak at $284.9 \mathrm{eV}$ and the $\mathrm{O} 1 \mathrm{~s}$ peak at $533.5 \mathrm{eV}$ [26-28]. Compared with $\mathrm{O} 1 \mathrm{~s}$, the $\mathrm{C} 1 \mathrm{~s}$ peak is obvious and sharp, and this confirms that the pristine MWCNTs have high purity and low degree of functionalization. For MWCNT-PDA, it is also clearly seen the $\mathrm{C} 1 \mathrm{~s}$ peak and O1s peak. But the intensity of $\mathrm{C} 1 \mathrm{~s}$ peak decreases and the intensity of $\mathrm{O} 1 \mathrm{~s}$ peak increases sharply. So, it is concluded that the PDA coating can bring in amounts of oxygen functional groups on the MWCNTs. What's more, there is a small peak appears at $402.2 \mathrm{eV}$. Though the intensity of this peak is weak, it represents $\mathrm{N}$ element and demonstrates the success of PDA modification. Table 2 summarizes the percentage of elements contained in the pristine MWCNTs and MWCNT-PDA. As displayed in Table 2, the content of $\mathrm{C}$ decreases from 95.76 to
Table 2. The element content of pristine MWCNTs and MWWCNTs-PDA of XPS analysis

\begin{tabular}{|l|c|c|c|c|c|}
\hline & $\begin{array}{c}\text { C1s } \\
{[\text { [At. \%] }}\end{array}$ & $\begin{array}{c}\text { O1s } \\
{[\text { [At. \%] }}\end{array}$ & $\begin{array}{c}\text { N1s } \\
\text { [At. \%] }\end{array}$ & O/C & N/C \\
\hline MWCNTs & 95.76 & 4.24 & 0.00 & 0.04 & 0.00 \\
\hline MWCNTs-PDA & 78.53 & 18.80 & 2.67 & 0.23 & 0.03 \\
\hline
\end{tabular}

$78.53 \%$ after PDA coating, while the content of oxygen and nitrogen increases from 4.24 to $18.80 \%$ and 0 to $2.67 \%$ respectively. All results of XPS indicate that the oxygen and nitrogen functional groups have grafted on the surface on MWCNTs after PDA coating.

\subsection{Morphology}

As displayed in HR-TEM images (Figure 6), the MWCNTs without modification cannot disperse well in matrix and have a certain degree of agglomerate, those agglomerates are discontinuous. On the other hand, the NR composites filled with the same content MWCNT-PDA (5 phr) shows a perfect dispersion, the MWCNT-PDA have a homogeneous dispersion in rubber matrix and connect consecutively with each other. The presence of the PDA layer results in the different dispersion of these two kinds of carbon nanotubes. The entanglements of MWCNT-PDA could be weakened and loosened by ultrasonic vibration (as shown in Figure 3), and then further break down during the mixture in open two-roll mill. In other words, there are two effective forces to improve the dispersion of MWCNT-PDA in rubber: the vibration force and shear force. For MWCNTs, ultrasonic vibration can hardly weaken and loosen its entanglements. There is only the shear force to disperse MWCNTs. This simple force is hard to destroy these entanglements fully in a short time. In conclusion, using appropriate modification of MWCNTs can make the MWCNTs disperse well in rubber.

\section{3. 'Payne effect'}

'Payne effect', which is the decrease of storage modulus $\left(G^{\prime}\right)$ with the increasing of strain, can represent the quality and strength of filler network in composite materials [29]. This non-linear behavior of filled rubber appeared at small strain range (below 100\%), so it was accepted by most researchers that the breakdown of network formed by filler agglomerates is the main reason for 'Payne effect' [30]. The value of $\Delta G^{\prime}$ (the difference between initial $G^{\prime}$ and final $G^{\prime}$ ) 


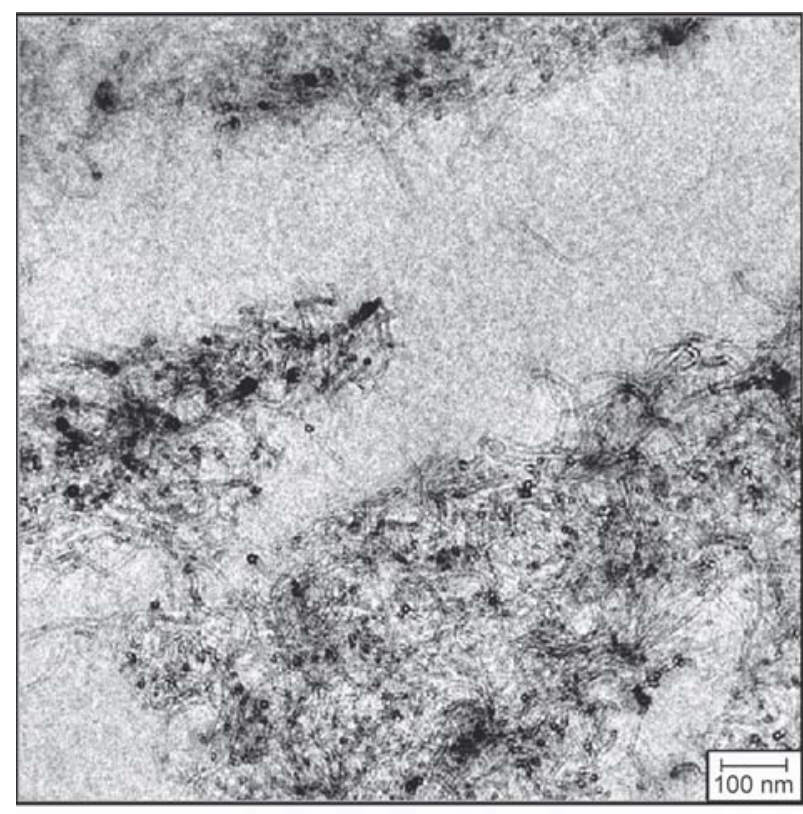

a)

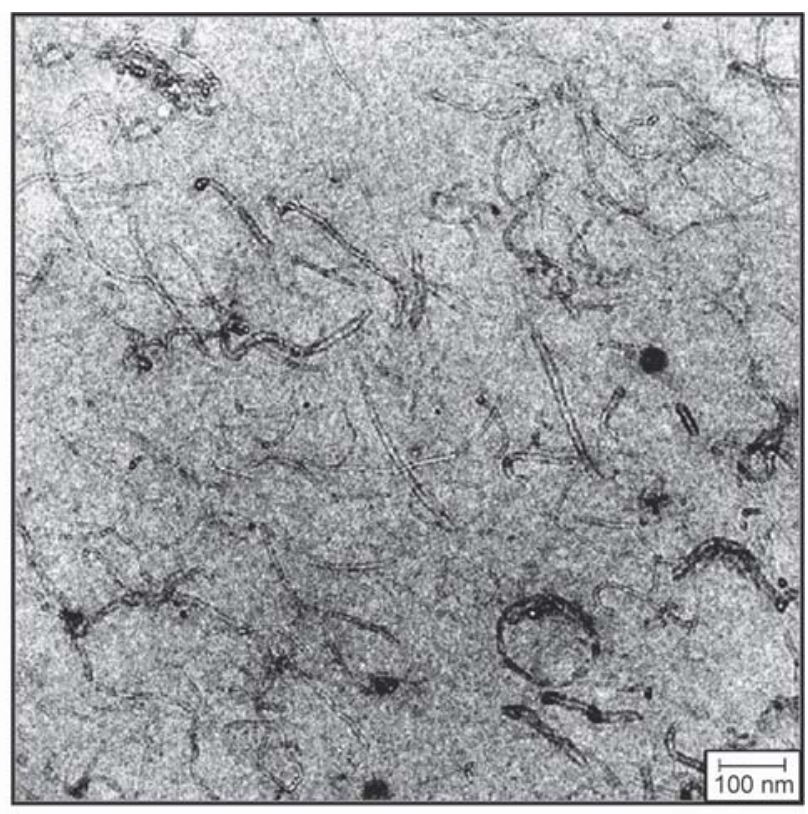

b)

Figure 6. The HR-TEM images of NR/MWCNTs (100/5) composite (a) and NR /MWCNTs-PDA (100/5) composite (b)

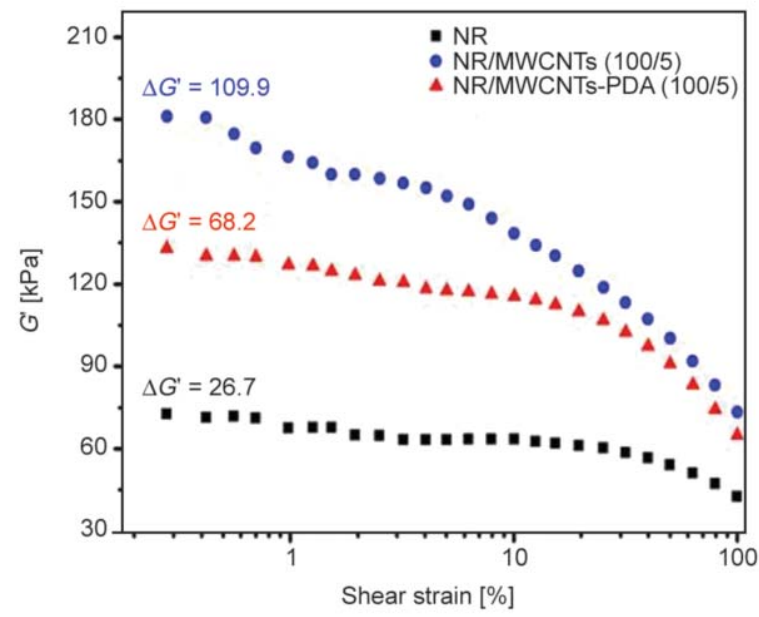

Figure 7. The storage modulus dependence on Strain of pure NR, NR/MWCNTs and NR/MWCNTs-PDA

is often used for quantification of the 'Payne effect'. The large amount of $\Delta G^{\prime}$ indicated the obvious 'Payne effect', the intense interaction of fillers and the poor dispersion of fillers. Figure 7 shows the different $G^{\prime}-$ strain behaviors of pure rubber and composites. The addition of MWCNTs or MWCNT-PDA makes the 'Payne effect' of composite materials more obvious, and the value of $\Delta G^{\prime}$ of NR/MWCNT-PDA composites is lower than that of the NR/MWCNT. This means the weaker filler-filler interactions between MWCNT-PDA and also demonstrates the good dispersion of MWCNT-PDA in NR composites.

\subsection{Vulcanization behavior and crosslink density}

As shown in Table 3, it can be seen that the scorch time $\left(t_{10}\right)$ and the optimum time $\left(t_{90}\right)$ decease after filling MWCNTs or MWCNT-PDA into NR. This result is consistent with the work reported by Nakaramontri et al. [9]. That is because the high thermal conductivity and good dispersion of MWCNTs prompt the uniform distribution of heat in matrix and quicken the crosslink reactions. But the curing rate index $(K)$ shows different changes with the addition of MWCNTs or MWCNT-PDA, the $K$ of NR/ MWCNT composites is higher than that of pure NR, while the $K$ of NR/MWCNT-PDA composites is not only below NR/MWCNTs, but also less than that of pure NR, we speculated it might be related to the PDA coating layer. In order to prove this speculation, the vulcanization characteristics of NR/PDA composites were measured. The result indicates that the curing rate of NR/MWCNT composites and NR/PDA composites is higher than that of pure NR, Therefore, it is concluded that PDA and MWCNTs could promote the vulcanization of rubber when they used alone. However, the MWCNT-PDA, as the combination of PDA and MWCNTs, does not promote the vulcanization of rubber, the K of NR/MWCNT-PDA composites is less than that of pure NR. It seemed that MWCNTs and PDA have negative synergistic effect 
Table 3. The vulcanization characteristics and crosslink density of pure NR and different NR composites

\begin{tabular}{|ll|c|c|c|c|}
\hline & NR & $\begin{array}{c}\text { NR/MWCNTs } \\
(\mathbf{1 0 0 / 5})\end{array}$ & $\begin{array}{c}\text { NR/MWCNTs-PDA } \\
(\mathbf{1 0 0} / \mathbf{5})\end{array}$ & $\begin{array}{c}\text { NR/PDA } \\
(\mathbf{1 0 0} / \mathbf{0 . 5})\end{array}$ \\
\hline$t_{10}$ & {$[\mathrm{~min}]$} & 5.9 & 3.0 & 2.0 & 3.7 \\
\hline$t_{90}$ & {$[\mathrm{~min}]$} & 8.5 & 5.5 & 4.8 & 6.2 \\
\hline$K$ & {$\left[\mathrm{~min}^{-1}\right]$} & 38.5 & 40.0 & 33.3 & 42.8 \\
\hline$M_{\mathrm{L}}[\mathrm{dNm}]$ & 6.2 & 13.2 & 13.8 & 13.8 \\
\hline$M_{\mathrm{H}}[\mathrm{dNm}]$ & 46.9 & 59.8 & 54.9 & 50.2 \\
\hline$\Delta M$ & {$[\mathrm{dNm}]$} & 40.7 & 46.6 & 41.1 & 36.4 \\
\hline$n_{\mathrm{c}}$ & {$\left[\cdot 10^{-4} \mathrm{~mol} / \mathrm{cm}\right]$} & $0.97 \pm 0.02$ & $1.32 \pm 0.01$ & $1.21 \pm 0.01$ & $0.84 \pm 0.02$ \\
\hline
\end{tabular}

$K$ : Curing rate index $(\mathrm{CRI}), K=100 /\left(t_{90}-t_{10}\right)$

on the promotion of vulcanization, which lead to the curing rate of NR/MWCNT-PDA is the least among these composites. Furthermore, whether MWCNTs or MWCNT-PDA can bring increase both in the minimal torque $\left(M_{\mathrm{L}}\right)$ and the maximal torque $\left(M_{\mathrm{H}}\right)$. But NR/MWCNTs is higher than NR/MWCNT-PDA in terms of $\triangle M$ (the different between $M_{\mathrm{H}}$ and $M_{\mathrm{L}}$ ). That could also be attributed to the introduction of PDA. In our opinion, the PDA coating on MWCNTs still has chemical activity and might participate in the vulcanization, and then affect the crosslink of rubber molecular. Therefore, even the vulcanization degree of NR/PDA is lower than that of pure NR.

The crosslink density $\left(n_{\mathrm{c}}\right)$ of NR and composites have been characterized by equilibrium swelling. It is found that the crosslink density of NR composite rises from $0.97 \cdot 10^{-4}$ to $1.32 \cdot 10^{-4} \mathrm{~mol} / \mathrm{cm}^{3}$ after filled $5 \mathrm{phr}$ MWCNTs; the crosslink density of NR/MWCNT-PDA composites is about $1.21 \cdot 10^{-4} \mathrm{~mol} / \mathrm{cm}^{3}$. Similar results have been reported in several literatures. Zhao et al. [31] have calculated the crosslink density according to MooneyRivlin formula, and found the crosslink density of NR with $0.25 \mathrm{wt} \%$ SWCNTs was slightly higher than that of the pure NR. They considered that the SWCNTs played a role of physical crosslink points in the process of vulcanization. This viewpoint could also explain our experimental results. Since the content of MWCNTs was $5 \mathrm{phr}$ (more than $0.25 \mathrm{wt} \%$ in literature), the role of MWCNTs in vulcanization was no longer the independent physical crosslink points but the network structure formed by the combination of MWCNTs (Figure 6). The network formed by the crosslink of rubber molecular chains interpenetrated in the network formed by MWCNTs. This is the reason why the crosslink density of NR/MWCNT composites increases. Besides, the rise of $n_{\mathrm{c}}$ brought by MWCNT-PDA is smaller than that of MWCNTs, and the $n_{\mathrm{c}}$ of NR/PDA is even lower than that of neat NR. This is consistent with the result of vulcanization degree and again proves the existence of negative influence of PDA toward the crosslinking of rubber molecular chains.

\subsection{Mechanical properties}

As shown in Table 4, the tensile strength of pure NR is about $20.2 \mathrm{MPa}$. After adding $5 \mathrm{phr}$ MWCNTs or MWCNT-PDA, the tensile strength of composites increases to 24.7 and $28.6 \mathrm{MPa}$ respectively; the latter is $22 \%$ higher than the former. However, the elongation at break of the composites decreases with the addition of MWCNTs or MWCNT-PDA. What is noteworthy is that the stress (at certain strain) of NR composites gets nearly twice enhancement after filling MWCNTs or MWCNT-PDA, and this remarkable increase could not be gained via adding the same loading of carbon black or silica [32, 33]. Furthermore, the stress of NR/MWCNTs is a little above NR/

Table 4. The mechanical properties of NR, NR/MWCNTs and NR/MWCNTs-PDA

\begin{tabular}{|ll|c|c|c|}
\hline & NR & $\begin{array}{c}\text { NR/MWCNTs } \\
(\mathbf{1 0 0 / 5 )}\end{array}$ & $\begin{array}{c}\text { NR/MWCNTs-PDA } \\
\mathbf{( 1 0 0 / 5 )}\end{array}$ \\
\hline Tensile strength & {$[\mathrm{MPa}]$} & $20.2 \pm 0.7$ & $24.7 \pm 1.2$ & $28.6 \pm 1.0$ \\
\hline Elongation at break & {$[\%]$} & $594 \pm 23$ & $530 \pm 16$ & $553 \pm 14$ \\
\hline Stress at $100 \%$ strain & {$[\mathrm{MPa}]$} & $1.09 \pm 0.3$ & $2.08 \pm 0.1$ & $1.97 \pm 0.1$ \\
\hline Stress at 300\% strain $[\mathrm{MPa}]$ & $3.47 \pm 0.2$ & $6.67 \pm 0.3$ & $6.52 \pm 0.4$ \\
\hline Shore A hardness & 43 & 56 & 54 \\
\hline
\end{tabular}


MWCNT-PDA. The hardness of NR/MWCNT composites is higher than that of NR/MWCNT-PDA. For the NR/MWCNT (5 phr) composites and NR/ MWCNT-PDA (5 phr) composites, the amount of MWCNT-PDA is the same as that of MWCNTs, because of the presence of the PDA coating layer, there are $4.5 \mathrm{phr}$ MWCNTs in the NR/MWCNT-PDA composites (100/5), though effective MWCNTs content of the NR/MWCNT-PDA is smaller than that of NR/MWCNT, the tensile strength of NR/MWCNTPDA is still higher than that of NR/MWCNT.

The reasons for the different changes in mechanical properties brought by MWCNTs and MWCNT-PDA could be analyzed as follows: under low strains (below 100\%), there are three types of forces that should be overcome in the process of stretching rubber composites, i.e. the restoring force of rubber molecular chains, the interactions between NR and fillers, and the interactions of fillers-fillers. Among them, the interactions of fillers-fillers and the restoring force of rubber molecular chains play a major role in this process. In our research, on the one hand, the $\Delta G^{\prime}$ of NR/MWCNT composites is higher than that of NR/MWCNT-PDA composites. So the interaction of the MWCNTs-MWCNTs is greater than the interaction of the MWCNT-PDA-MWCNT-PDA. On the other hand, the crosslink density of NR/ MWCNTs (5 phr) composites is higher than that of NR/MWCNT-PDA ( 5 phr) composites. So the restoring force of rubber molecular chains of NR/MWCNT composites is higher than that of NR/MWCNT-PDA composites, because the restoring force of rubber molecular chains is related to the crosslink density. The higher the crosslink density, the bigger the restoring force will be. Based on the above analysis, we can conclude that the stress of NR/MWCNTs ( $5 \mathrm{phr}$ ) composites is higher than that of NR/MWCNT-PDA (5 phr) composites at low strains, the Young's modulus of NR/MWCNTs ( $5 \mathrm{phr}$ ) composites is higher than that of NR/MWCNT-PDA (5 phr) composites too. This is consistent with the stress-strain curve. At high strains (above 100\%), the interactions of fillersfillers is negligible because of the breakdown of fillers-fillers network (shown in Figure 8). But the restoring force of rubber molecular chains is the main force to be overcome. This force is related to the crosslink density. Therefore, the stress under high strains of NR/MWCNT composites with high cross-

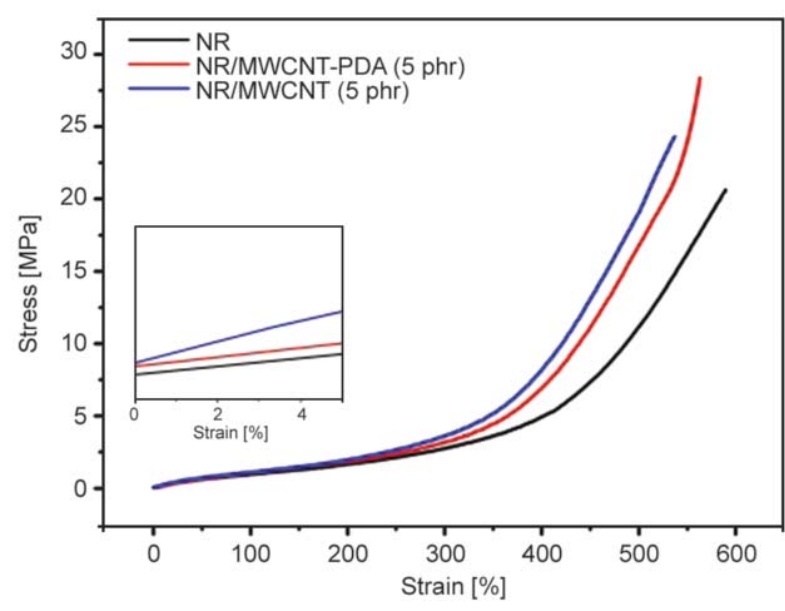

Figure 8. The stress-strain curve of the composites and pure NR

link density is also bigger than that of NR/MWCNTPDA composites. With the gradual increase of strain, the NR/MWCNT composites start to break first. That is because the entanglements of MWCNTs readily become the stress concentration points. In addition, it is acknowledged that NR is a kind of self-reinforced polymer for the strain-induced crystallization [34]. The higher elongation means the longer continuation of strain-induced crystallization. So, the NR/MWCNT-PDA composites have higher tensile strength than that of NR/MWCNT composites.

\subsection{Electrical conductivity}

Figure 9 shows the effect of MWCNT loading on the electrical conductivity of NR composites. It is found that the volume resistivity of NR composites almost keeps the same value when the content of MWCNTs or MWCNT-PDA is low ( $\leq 1 \mathrm{phr})$. With the increas-

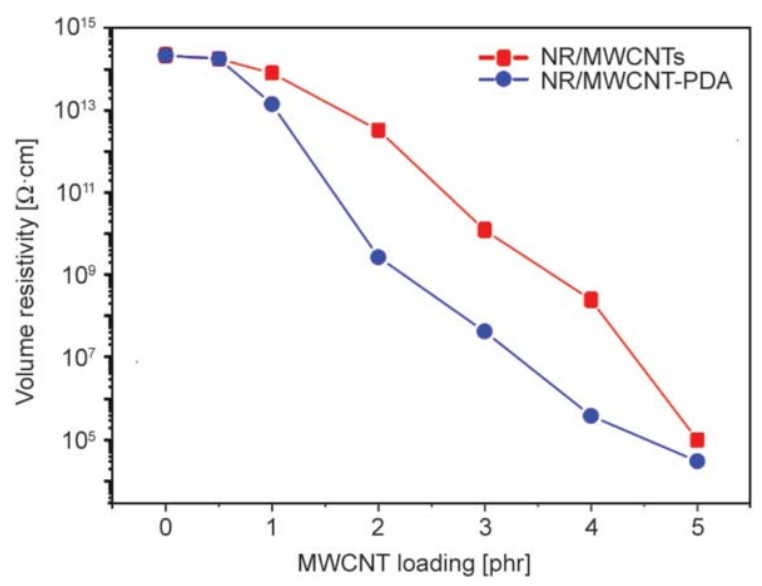

Figure 9. The effect of MWCNTs content on the volume resistivity of NR composite 
ing of filler content, the resistivity starts to decrease. But these two samples display different dropping rates, especially at 2 phr MWCNTs content. The volume resistivity of NR/MWCNT-PDA composites falls to about $2.7 \cdot 10^{9} \Omega \cdot \mathrm{cm}$, compared with $3.3 \cdot 10^{13} \Omega \cdot \mathrm{cm}$ of NR/MWCNT composites. When filled with $5 \mathrm{phr}$ MWCNT-PDA, the resistivity decreases abruptly by 10 orders of magnitude, and the rubber material has changed from an insulator into a semiconductor, which is known as percolation phenomenon. Although the $5 \mathrm{phr}$ MWCNTs also can bring a big drop in volume resistivity of NR, the electrical conductivity of NR/MWCNT-PDA is better than that of NR/MWCNTs. On account of high aspect ratio and excellent electrical conductivity, MWCNTs is often incorporated into rubber materials for functionalization. Kummerlöwe [35] have found that a percolation threshold smaller than $2 \mathrm{wt} \% \mathrm{CNT}$ was reached in the NBR/CNT composites. It is suggested that the good dispersion and the formation of continuous network of the carbon nanotubes are the main reasons for the sudden rise in electrical conductivity [36]. Good dispersion not only ensures the formation of fillers-fillers networks at low content, but also is helpful to take full advantage of the property of MWCNTs. In conclusion, the effect of MWCNTs on the electrical conductivity of rubbers is remarkable, and the loading required is less than $5 \mathrm{phr}$.

\subsection{Thermal conductivity}

Generally, there are several factors determining the thermal conductivity of filled elastomers, including the properties of filler (shape, size and thermal conductivity), the content of filler and the thermal conductivity of matrix [37]. Since the thermal conductivity of traditional fillers is not very high (such as alumina: $20 \sim 30 \mathrm{~W} /(\mathrm{m} \cdot \mathrm{K})$; boron nitride: $250 \sim$ $300 \mathrm{~W} /(\mathrm{m} \cdot \mathrm{K})$ [38]), it is needed to fill a large number of traditional fillers for preparation polymer composites which have high thermal conductivity. But this approach not only increases the cost of production but also reduces other performances of composites. Filling MWCNTs into polymer makes it possible to prepare a new composite with good thermal conductivity and low filler loading. Figure 10 shows the thermal conductivity of NR composites with different MWCNT loading. It can be seen that the thermal conductivity gradually rises with the increasing

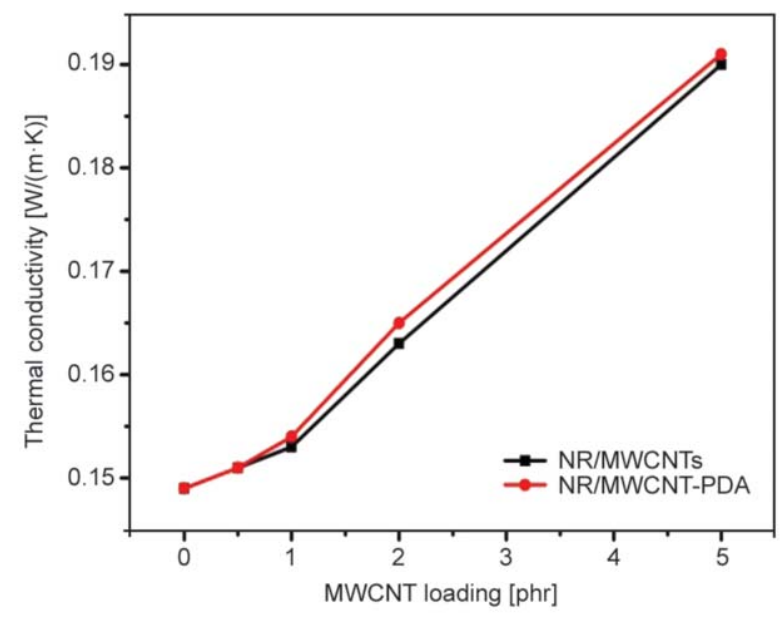

Figure 10. The effect of MWCNTs content on the thermal conductivity of NR composite

of MWCNTs. When filled with 5 phr MWCNTs, the thermal conductivity increases from 0.149 to $0.190 \mathrm{~W} /(\mathrm{m} \cdot \mathrm{K})$, with the growth rate of $27.5 \%$. And the thermal conductivity of NR/MWCNTs-PDA (5 phr) is $0.191 \mathrm{~W} /(\mathrm{m} \cdot \mathrm{K})$; the improvement is also only $28.2 \%$. The similar results also were reported by Das et al. [36]. They have found that the thermal conductivity of SBR-BR increased from 0.08 to $0.13 \mathrm{~W} /(\mathrm{m} \cdot \mathrm{K})$ after filling $4 \mathrm{phr}$ MWCNTs. Gardea et al. [39] revealed that the thermal conductivity of epoxy increased from 0.297 to $0.313 \mathrm{~W} /(\mathrm{m} \cdot \mathrm{K})$ when the content of CNTs was $0.6 \mathrm{wt} \%$. As far as the upto-date study is concerned, a small amount of MWCNTs cannot dramatically improve the thermal conductivity of polymer.

The possible reasons are analyzed as follows. Firstly, the high aspect ratio of MWCNTs is inevitably damaged under ultrasonic vibration and shear force, for the outstanding thermal conductivity of MWCNTs is dependent on its high aspect ratio [14]. So the thermal conductivity of MWCNTs dispersed in NR composites is less than that of the original one. Secondly, there might be large interface thermal resistances between MWCNTs and rubber. Heat conduction in MWCNTs and rubber is dependent on the transmission of phonon. Due to the mismatch of vibration frequency and the imperfect contact between MWCNTs and rubber, the phonon scattering which hinders the heat conduction inevitably happens in the interface [40].

In order to explore the main reason why MWCNTs cannot significantly increase the thermal conductivity of natural rubber, a thermal conductivity model 
proposed by Nan [41] was introduced. In this model, there were four factors that affected the thermal conductivity of the composites, which were the length and diameter of MWCNTs, the content of MWCNTs and the interface thermal resistance between MWCNTs and matrix. This model is based on conventional Maxwell-Garnett (MG) approximation, and there are two premises for its application: MWCNTs randomly disperse in a matrix, neglecting interparticle multiple scattering; the matrix/MWCNT interface is assumed to be effective for the transport of energy across it. Its formulas are depicted by the Equations (2) and (3):

$$
\begin{aligned}
& \frac{K_{\mathrm{e}}}{K_{\mathrm{m}}}=\frac{3+f\left(\beta_{\mathrm{x}}+\beta_{\mathrm{z}}\right)}{3-f \beta_{\mathrm{x}}} \\
& \beta_{\mathrm{x}}=\frac{2\left(K_{11}^{\mathrm{c}}-K_{\mathrm{m}}\right)}{K_{11}^{\mathrm{c}}+K_{\mathrm{m}}}, \quad \beta_{\mathrm{z}}=\frac{K_{33}^{\mathrm{c}}}{K_{\mathrm{m}}}-1, \\
& K_{11}^{\mathrm{c}}=\frac{K_{\mathrm{c}}}{1+\frac{2 \alpha_{\mathrm{k}}}{d} \cdot \frac{K_{\mathrm{c}}}{K_{\mathrm{m}}}}, \quad K_{33}^{\mathrm{c}}=\frac{K_{\mathrm{c}}}{1+\frac{2 \alpha_{\mathrm{k}}}{l} \cdot \frac{K_{\mathrm{c}}}{K_{\mathrm{m}}}} \\
& \alpha_{\mathrm{k}}=R_{\mathrm{k}} K_{\mathrm{m}}
\end{aligned}
$$

where $K_{\mathrm{e}}$ is the thermal conductivity of composite, $K_{\mathrm{m}}$ is the thermal conductivity of matrix, $K_{\mathrm{c}}$ is the thermal conductivity of filler, $f$ is the volume fraction of filler, the $K_{11}^{\mathrm{c}}$ and $K_{33}^{\mathrm{c}}$ are the thermal conductivities along transverse and longitudinal axes of a composite unit cell, $\alpha_{\mathrm{k}}$ is Kapitza radius, $R_{\mathrm{k}}$ is Kapitza resistance, $d$ is the diameter of CNTs, $l$ is the length of CNTs.

In our research, this model is used to calculate the thermal conductivity of the composites with different interface thermal resistance and different lengths of carbon nanotubes. The parameters used for the calculation are listed below:

$d=15 \mathrm{~nm} ; K_{\mathrm{m}}=0.149 \mathrm{~W} /(\mathrm{m} \cdot \mathrm{K})$.

When the content of MWCNTs is certain $(f=0.0315)$, the effect of interfacial thermal resistance and the length of MWCNTs on the thermal conductivity of composites is discussed. The relationship between thermal conductivity and length of MWCNTs is obtained based on the research of Mingo [42]. As shown in Figure 10, when the length of the MWCNTs is certain, the thermal conductivity of the NR composites decreases sharply with the increase of the interface thermal resistance. For instance, when the length of the MWCNTs is $600 \mathrm{~nm}$, and the $\alpha_{\mathrm{k}}$ grow- ing from 0 to $10 \mathrm{~nm}$, the thermal conductivity of the NR composites decreases by $97.93 \%$ (from 9.32 to $0.19 \mathrm{~W} /(\mathrm{m} \cdot \mathrm{K}))$. When the interface thermal resistance is low $\left(\alpha_{\mathrm{k}}<5 \mathrm{~nm}\right)$, the thermal conductivity of the composites gets higher with the increased length of MWCNTs. For instance, the thermal conductivity of the NR composites increases from 0.31 to $1.17 \mathrm{~W} /(\mathrm{m} \cdot \mathrm{K})$ when the length of the MWCNTs increased from 200 to $1400 \mathrm{~nm}$ and $\alpha_{\mathrm{k}}$ is $1 \mathrm{~nm}$, which increased by $277.42 \%$. When the interface thermal resistance is higher $\left(\alpha_{k}>7 \mathrm{~nm}\right)$, with the increase of the length of the MWCNTs, the thermal conductivity of the NR composites is not significantly increased. For instance, when $\alpha_{\mathrm{k}}$ is $10 \mathrm{~nm}$, and the length of the MWCNTs increased from 200 to $1400 \mathrm{~nm}$, the thermal conductivity of the NR composites increases from 0.16 to $0.25 \mathrm{~W} /(\mathrm{m} \cdot \mathrm{K})$, which only increased by $56.25 \%$.

As shown in Figure 11, the effect of interfacial thermal resistance and the content of MWCNTs on the thermal conductivity of composites are also discussed. The statistics of the length of carbon nanotubes in TEM images indicated that the average value was $450 \mathrm{~nm}$. Based on the study of Mingo [42], the value of $K_{\mathrm{c}}$ could be calculated, and the result was $800 \mathrm{~W} /(\mathrm{m} \cdot \mathrm{K})$. The solid line in Figure 12 stands for the calculated thermal conductivity of NR composites; the solid dot represents the experimental value of the thermal conductivity of the composite. It is evident that the thermal conductivity of the com-

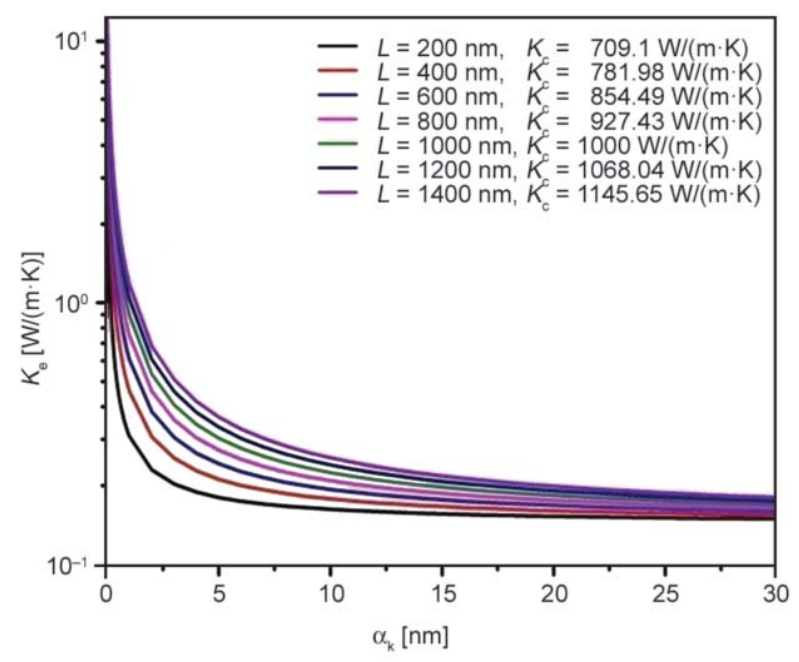

Figure 11. The effect of interfacial thermal resistance and the length of carbon nanotubes on the thermal conductivity of composites, solid lines are predicted by using Equation (2) for different length of CNTs 


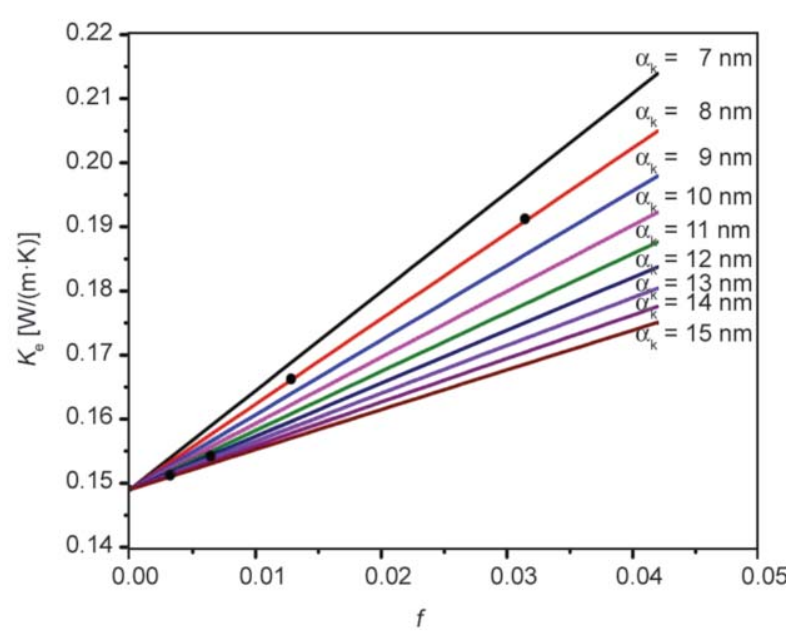

Figure 12. The effect of interfacial thermal resistance and the content of carbon nanotubes on the thermal conductivity of composites, solid lines are predicted by using Equation (2) for different Kapitza radius, solid dots are experimental value of the thermal conductivity of the composites

posites decreases with the increase of the interface thermal resistance. With the increase of MWCNTs content, the experimental value falls in the curve of the lower interface thermal resistance, which is because a path of heat conduction has been formed when the filler content increases.

As can be found from the above analysis, in our research, the $\alpha_{k}$ of the NR/MWCNT composites is above $7 \mathrm{~nm}$; in this case, the length of the carbon nanotube has a little effect on the thermal conductivity of the composites. Therefore, the interface thermal resistance is the main reason why the MWCNTs or MWCNT-PDA cannot significantly increase the thermal conductivity of natural rubber.

\section{Conclusions}

Coated by PDA successfully, the MWCNTs not only became hydrophilic but also showed good dispersion in NR. Compared with NR/MWCNTs, the NR composites filled with MWCNT-PDA had higher tensile strength and elongation, but gained less improvement in stress at certain strain; it was attributed to the different dispersions and crosslink densities. The volume resistance of NR/MWCNT-PDA was found to be lower than NR/MWCNT due to the better dispersion and the more complete filler network. The super electrical conductivity allows this nano composite widely used in automobiles, electrical appliances, architecture and other fields. An increase in thermal conductivity by almost $28 \%$ could be achieved for NR by incorporation 5 phr MWCNTs or MWCNTPDA. The slight improvement was mainly due to the existence of big interfacial thermal resistance between CNTs and rubber.

\section{Acknowledgements}

The authors would like to acknowledge the National Basic Research Program of China (973 Program) Project (2011CB932603, 2015CB654703, 2015CB654704) as well as New Century Excellent Talents in University (Grant contract No. NCET-12-0762), National Natural Science Foundation (contract grant number: 50873007), Program for Changjiang Scholars and Innovative Research Team in University (contract grant number, IRT0807), and Opening Project of State Key Laboratory of Polymer Materials Engineering, Sichuan University (contract grant number: KF200902) for their financial support to this study.

\section{References}

[1] Baughman R. H., Zakhidov A. A., de Heer W. A.: Carbon nanotubes - The route toward applications. Science, 297, 787-792 (2002).

https://doi.org/10.1126/science. 1060928

[2] Coleman J. N., Khan U., Blau W. J., Gun'ko Y. K.: Small but strong: A review of the mechanical properties of carbon nanotube-polymer composites. Carbon, 44, 16241652 (2006). https://doi.org/10.1016/j.carbon.2006.02.038

[3] Ponnamma D., Sadasivuni K. K., Grohens Y., Guod Q., Thomas S.: Carbon nanotube based elastomer composites - An approach towards multifunctional materials. Journal of Materials Chemistry C, 2, 8446-8485 (2014). https://doi.org/10.1039/c4tc01037j

[4] Kummerlöwe C., Vennemann N., Pieper S., Siebert A., Nakaramontri Y.: Preparation and properties of carbonnanotube composites with natural rubber and epoxidized natural rubber. Polimery, 59, 811-818 (2014). https://doi.org/10.14314/polimery.2014.811

[5] Subramaniam K., Das A., Stöckelhuber K. W., Heinrich G.: Elastomer composites based on carbon nanotubes and ionic liquid. Rubber Chemistry and Technology, 86, 367-400 (2013).

https://doi.org/10.5254/rct.13.86984

[6] Lorenz H., Fritzsche J., Das A., Stöckelhuber K. W., Jurk R., Heinrich G., Klüppel M.: Advanced elastomer nanocomposites based on CNT-hybrid filler systems. Composites Science and Technology, 69, 2135-2143 (2009). https://doi.org/10.1016/j.compscitech.2009.05.014

[7] Bokobza L., Belin C.: Effect of strain on the properties of a styrene-butadiene rubber filled with multiwall carbon nanotubes. Journal of Applied Polymer Science, 105, 2054-2061 (2007).

https://doi.org/10.1002/app.26153 
[8] Bokobza L., Kolodziej M.: On the use of carbon nanotubes as reinforcing fillers for elastomeric materials. Polymer International, 55, 1090-1098 (2006). https://doi.org/10.1002/pi.2064

[9] Nakaramontri Y., Kummerlöwe C., Nakason C., Vennemann N.: The effect of surface functionalization of carbon nanotubes on properties of natural rubber/carbon nanotube composites. Polymer Composites, 36, 2113 2122 (2015).

https://doi.org/10.1002/pc.23122

[10] Fritzsche J., Lorenz H., Klüppel M.: CNT based elastomer-hybrid-nanocomposites with promising mechanical and electrical properties. Macromolecular Materials and Engineering, 294, 551-560 (2009). https://doi.org/10.1002/mame.200900131

[11] Nah C., Lim J. Y., Cho B. H., Hong C. K., Gent A. N.: Reinforcing rubber with carbon nanotubes. Journal of Applied Polymer Science, 118, 1574-1581 (2010). https://doi.org/10.1002/app.32524

[12] Shanmugharaj A. M., Bae J. H., Lee K. Y., Noh W. H., Lee S. H., Ryu S. H.: Physical and chemical characteristics of multiwalled carbon nanotubes functionalized with aminosilane and its influence on the properties of natural rubber composites. Composites Science and Technology, 67, 1813-1822 (2007).

https://doi.org/10.1016/j.compscitech.2006.10.021

[13] Barroso-Bujans F., Verdejo R., Pérez-Cabero M., Agouram S., Rodríguez-Ramos I., Guerrero-Ruiz A., LopezManchado M. A.: Effects of functionalized carbon nanotubes in peroxide crosslinking of diene elastomers. European Polymer Journal, 45, 1017-1023 (2009). https://doi.org/10.1016/j.eurpolymj.2008.12.029

[14] Wang Z. L., Tang D. W., Li X. B., Zheng X. H., Zhang W. G., Zheng L. X., Zhu Y. T., Jin A. Z., Yang H. F., Gu C. Z.: Length-dependent thermal conductivity of an individual single-wall carbon nanotube. Applied Physics Letters, 91, 123113-123119 (2007). https://doi.org/10.1063/1.2779850

[15] Jo J. O., Saha P., Kim N. G., Ho C. C., Kim J. K.: Development of nanocomposite with epoxidized natural rubber and functionalized multiwalled carbon nanotubes for enhanced thermal conductivity and gas barrier property. Materials and Design, 83, 777-785 (2015). https://doi.org/10.1016/j.matdes.2015.06.045

[16] Joseph N., Janardhanan C., Sebastian M. T.: Electromagnetic interference shielding properties of butyl rubber-single walled carbon nanotube composites. Composites Science and Technology, 101, 139-144 (2014). https://doi.org/10.1016/j.compscitech.2014.07.002

[17] George N., Chandra J. C. S., Mathiazhagan A., Joseph R.: High performance natural rubber composites with conductive segregated network of multiwalled carbon nanotubes. Composites Science and Technology, 116, 33-40 (2015).

https://doi.org/10.1016/j.compscitech.2015.05.008
[18] Lee H., Dellatore S. M., Miller W. M., Messersmith P. B.: Mussel-inspired surface chemistry for multifunctional coatings. Science, 318, 426-430 (2007). https://doi.org/10.1126/science.1147241

[19] Hao M., Tang M., Wang W., Tian M., Zhang L., Lu Y.: Silver-nanoparticle-decorated multiwalled carbon nanotubes prepared by poly(dopamine) functionalization and ultraviolet irradiation. Composites Part B: Engineering, 95, 395-403 (2016).

https://doi.org/10.1016/j.compositesb.2016.03.084

[20] Subramanian A. S., Tey J. N., Zhang L., Ng B. H., Roy S., Wei J., Hu X.: Synergistic bond strengthening in epoxy adhesives using polydopamine/MWCNT hybrids. Polymer, 82, 285-294 (2016). https://doi.org/10.1016/j.polymer.2015.11.031

[21] Xi Z-Y., Xu Y-Y., Zhu L-P., Wang Y., Zhu B-K.: A facile method of surface modification for hydrophobic polymer membranes based on the adhesive behavior of poly (DOPA) and poly(dopamine). Journal of Membrane Science, 327, 244-253 (2009).

https://doi.org/10.1016/j.memsci.2008.11.037

[22] Lu Y. L., Xu T. Y., Wang W. C., Zhang L. Q.: Dopamine modified carbon nanotube/rubber composite material and preparation method thereof (in Chinese). CN Patent 102321279, China (2013).

[23] Flory P. J.: Phase equilibria in solutions of rod-like particles. Proceedings of the Royal Society A: Mathematical, Physical and Engineering Sciences, 234, 73-89 (1956). https://doi.org/10.1098/rspa.1956.0016

[24] Fei B., Qian B., Yang Z., Wang R., Liu W. C., Mak C. L., Xin J. H.: Coating carbon nanotubes by spontaneous oxidative polymerization of dopamine. Carbon, 46, 1795-1797 (2008).

https://doi.org/10.1016/j.carbon.2008.06.049

[25] Jiang H-X., Ni Q-Q., Natsuki T.: Design and evaluation of the interface between carbon nanotubes and natural rubber. Polymer Composites, 32, 236-242 (2011). https://doi.org/10.1002/pc. 21040

[26] Sham M-L., Kim J-K.: Surface functionalities of multiwall carbon nanotubes after UV/ozone and TETA treatments. Carbon, 44, 768-777 (2006).

https://doi.org/10.1016/j.carbon.2005.09.013

[27] Barthos R., Méhn D., Demortier A., Pierard N., Morciaux Y., Demortier G., Fonseca A., Nagy J. B.: Functionalization of single-walled carbon nanotubes by using alkyl-halides. Carbon, 43, 321-325 (2005).

https://doi.org/10.1016/j.carbon.2004.09.018

[28] Hu H., Zhao B., Hamon M. A., Kamaras K., Itkis M. E., Haddon R. C.: Sidewall functionalization of singlewalled carbon nanotubes by addition of dichlorocarbene. Journal of the American Chemical Society, 125, 14893-14900 (2003). https://doi.org/10.1021/ja0356737

[29] Payne A. R., Whittaker R. E.: Low strain dynamic properties of filled rubbers. Rubber Chemistry and Technology, 44, 440-478 (1971).

https://doi.org/10.5254/1.3547375 
[30] Wang M-J.: Effect of polymer-filler and filler-filler interactions on dynamic properties of filled vulcanizates. Rubber Chemistry and Technology, 71, 520-589 (1998). https://doi.org/10.5254/1.3538492

[31] Zhao Q., Tannenbaum R., Jacob K. I.: Carbon nanotubes as Raman sensors of vulcanization in natural rubber. Carbon, 44, 1740-1745 (2006).

https://doi.org/10.1016/j.carbon.2005.12.035

[32] Rattanasom N., Saowapark T., Deeprasertkul C.: Reinforcement of natural rubber with silica/carbon black hybrid filler. Polymer Testing, 26, 369-377 (2007). https://doi.org/10.1016/j.polymertesting.2006.12.003

[33] Peng Z., Kong L. X., Li S-D., Chen Y., Huang M. F.: Self-assembled natural rubber/silica nanocomposites: Its preparation and characterization. Composites Science and Technology, 67, 3130-3139 (2007). https://doi.org/10.1016/j.compscitech.2007.04.016

[34] Weng G., Huang G., Qu L., Nie Y., Wu J.: Large-scale orientation in a vulcanized stretched natural rubber network: Proved by in situ synchrotron X-ray diffraction characterization. The Journal of Physical Chemistry B, 114, 7179-7188 (2010). https://doi.org/10.1021/jp100920g

[35] Kummerlöwe C., Vennemann N., Yankova E., Wanitschek M., Größ C., Heider T., Haberkorn F., Siebert A.: Preparation and properties of carbon nanotube composites with nitrile- and styrene-butadiene rubbers. Polymer Engineering and Science, 53, 849-856 (2013). https://doi.org/10.1002/pen.23332
[36] Das A., Stöckelhuber K. W., Jurk R., Saphiannikova M., Fritzsche J., Lorenz H., Klüppel, M., Heinrich G.: Modified and unmodified multiwalled carbon nanotubes in high performance solution-styrene-butadiene and butadiene rubber blends. Polymer, 49, 5276-5283 (2008). https://doi.org/10.1016/j.polymer.2008.09.031

[37] Kemaloglu S., Ozkoc G., Aytac A.: Properties of thermally conductive micro and nano size boron nitride reinforced silicon rubber composites. Thermochimica Acta, 499, 40-47 (2010). https://doi.org/10.1016/j.tca.2009.10.020

[38] Han Z., Fina A.: Thermal conductivity of carbon nanotubes and their polymer nanocomposites: A review. Progress in Polymer Science, 36, 914-944 (2011). https://doi.org/10.1016/j.progpolymsci.2010.11.004

[39] Gardea F., Lagoudas D. C.: Characterization of electrical and thermal properties of carbon nanotube/epoxy composites. Composites Part B: Engineering, 56, 611620 (2014).

https://doi.org/10.1016/j.compositesb.2013.08.032

[40] Shenogin S., Xue L., Ozisik R., Keblinski P., Cahill D. G.: Role of thermal boundary resistance on the heat flow in carbon-nanotube composites. Journal of Applied Physics, 95, 8136-8144 (2004).

https://doi.org/10.1063/1.1736328

[41] Nan C-W., Shi Z., Lin Y.: A simple model for thermal conductivity of carbon nanotube-based composites. Chemical Physics Letters, 375, 666-669 (2003). https://doi.org/10.1016/S0009-2614(03)00956-4

[42] Mingo N., Broido D. A.: Length dependence of carbon nanotube thermal conductivity and the 'problem of long waves'. Nano Letters, 5, 1221-1225 (2005). https://doi.org/10.1021/n1050714d 